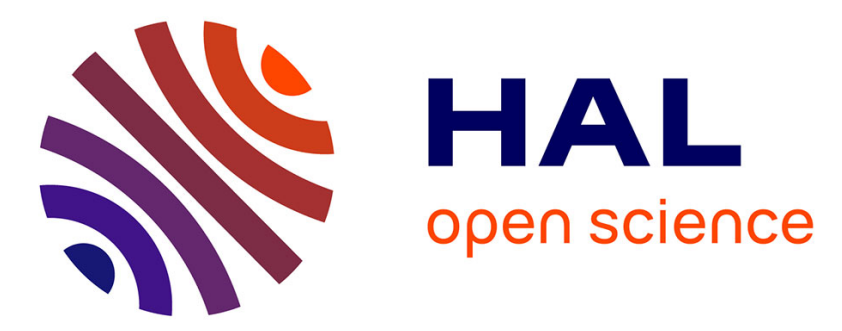

\title{
Optimization-based energy management strategies for electric vehicles.
}

\author{
Imad Eddine Aiteur, Cristina Vlad, Emmanuel Godoy
}

\section{To cite this version:}

Imad Eddine Aiteur, Cristina Vlad, Emmanuel Godoy. Optimization-based energy management strategies for electric vehicles.. IECON 2015, Nov 2015, Yokohama, Japan. 10.1109/iecon.2015.7392634 . hal-01257827

\section{HAL Id: hal-01257827}

https://hal-centralesupelec.archives-ouvertes.fr/hal-01257827

Submitted on 16 Mar 2020

HAL is a multi-disciplinary open access archive for the deposit and dissemination of scientific research documents, whether they are published or not. The documents may come from teaching and research institutions in France or abroad, or from public or private research centers.
L'archive ouverte pluridisciplinaire HAL, est destinée au dépôt et à la diffusion de documents scientifiques de niveau recherche, publiés ou non, émanant des établissements d'enseignement et de recherche français ou étrangers, des laboratoires publics ou privés. 


\title{
Optimization-based energy management strategies for electric vehicles
}

\author{
Imad Eddine Aiteur, Cristina Vlad and Emmanuel Godoy \\ Laboratoire des Signaux et Systèmes (L2S, UMR CNRS 8506) \\ CentraleSupélec-CNRS-Université Paris-Sud \\ Automatic Control Department \\ 3 , rue Joliot Curie \\ 91192, Gif-sur-Yvette cedex, France \\ E-mail: \{imad-eddine.aiteur, cristina.vlad, emmanuel.godoy\}@centralesupelec.fr
}

\begin{abstract}
This article analyses three energy management strategies for an electric vehicle powertrain in order to maximize its global efficiency. The considered electric motor supply system is a multi-source system that consists of a fuel cell as a main energy source and an additional element that supplies peak power (at start-up and during fast transients) and charges by regenerative braking. Energy management is achieved by formulating an optimization problem, aiming to minimize the fuel cell hydrogen mass consumption while satisfying the system physical constraints (strictly positive fuel cell power, limited capacity of the storage element). First, the optimization is realized using dynamic programming, an off-line optimization method that requires the knowledge of the entire power load profile. Secondly, two on-line optimization approaches are used: the equivalent consumption management strategy and the model predictive control strategy, for which only the current power demand or its knowledge over a finite time horizon are demanded. The optimization strategies are tested in simulation using a power load profile that corresponds to an urban driving cycle.
\end{abstract}

\section{INTRODUCTION}

The continuing increase of conventional energy consumption and the environmental concerns related to $\mathrm{CO}_{2}$ emissions encourage the use of alternative energy, provided by electric power sources for example. In the automotive field, multisource power supply systems have been considered for the propulsion system design of electric vehicles. An interesting choice for the primary power source is the fuel cell (FC) due to its high energy density [1]. However, the slow dynamics of the FC requires the use of a secondary storage element (battery, supercapacitor) capable to supply the power demand during the fast transients and to recover energy during the braking phase. In the literature, there are several possible architectures for multiple sources interconnection (series, cascade or parallel architecture) [2]. In this article, energy management strategies are investigated for a parallel architecture of an electric vehicle supply system.

Due to the presence of multiple energy sources (FC and secondary storage element), a supervision system for energy management is necessary to handle the energy flow and to optimize the system efficiency in terms of fuel consumption. Based on the power demand, the supervision system computes, at each sampling time, the power that each source has to supply. Generally, the energy management strategies (EMS) are divided in ruled-based (RB) and optimization-based strategies.
The RB strategies - deterministic RB [3], fuzzy RB [4], [5] approaches - use if-then rules that require the definition of a large number of threshold values. The optimization-based strategies can be classified in off-line and on-line methods based on the knowledge of the power load profile. Usually, the EMS performances are evaluated using standard or realworld driving cycles.

Off-line methods consist in designing the optimization algorithm with the full knowledge of the driving cycle, and therefore, of the power demand. An optimization resolution using Pontyagin's minimum principle [6], which provides a local optimal solution, has been applied to reduce the fuel consumption and the $\mathrm{CO}_{2}$ emissions for hybrid vehicles, using an internal combustion engine as primary source [7]. Also, dynamic programming (DP) has been used for energy management of hybrid [8], [9] and electric vehicles [10]. DP method [11] is based on the Bellman's principle of optimality and presents the advantage of providing necessary optimality conditions (global optimal solution) despite the substantial computational time. In addition to this, the real-time implementation is limited by the high memory capacity necessary to store the computed solution.

On-line strategies use the current power demand, without a prior knowledge of the driving cycle. Thus, these methods are suitable for real-time applications taking into account their low computational complexity. However, the optimization solution found at each sampling time represents a local optimal solution with respect to the power demand over the whole driving cycle. One of the methods employed in several studies is the equivalent consumption minimization strategy (ECMS) [12], [13] which has been applied on both electric [14] and hybrid [15], [16] vehicles. For electric vehicles, this strategy is based on the conversion of the electric power into equivalent hydrogen mass consumption of the FC. Another on-line method is represented by the model predictive control (MPC) that has been applied on electric vehicles for FC power optimization [17] and oxygen control [18]. The MPC strategy minimizes a cost function over a fine time horizon at each sampling instant, subject to model dynamics and constraints on the model inputs and states.

The objective of this article is to highlight the performances of two sub-optimal approaches (ECMS and MPC) 
in comparison to a reference optimal approach (DP), which provides a global optimal solution that cannot be exploited on an embedded system due to its high complexity. Thus, this article is organized as follows: Section II describes the model of the electric vehicle power supply system. In Section III, the optimization problem is formulated for different EMS: DP, ECMS and MPC. Section IV presents simulations results and an EMS comparison in terms of hydrogen mass consumption. Finally, conclusions and perspectives of this work are given in Section V.

\section{Power Supply System Modeling}

A parallel architecture of the multi-source system has been considered, which ensures a more effective power distribution control [2]. It consists on the connection of a fuel cell (FC) and a secondary storage element (SSE) to the DC link, using two DC-DC power electronic devices: a step-up converter and a bi-directional converter, as illustrated in Fig. 1. The presence of these auxiliary devices allows the DC voltage regulation that increases the system performance. Besides, from power optimization perspective, their conversion efficiency interferes in the power balance equation.

\section{A. Fuel cell model}

The fuel cell is an electrochemical device that converts chemical energy into electrical energy through an oxidation reduction reaction between a fuel (hydrogen) and oxygen from air [19]. In this study, a polymer electrolyte membrane fuel cell (PEMFC) is considered, which is often used for automotive applications due to its properties: small volume and weight, high power density, low temperature allowing fast start-up. In fact, a FC system is used, composed principally of: stack, air compressor, hydrogen tank and humidifier [20]. An accurate but complex non-linear dynamic model of the FC system is the Pukrushpan's model. Based on this reference model and on the following hydrogen flow expression:

$$
\phi_{H_{2}}=\frac{N_{c e l l} M_{H_{2}}}{n_{e^{-1}} F} I_{f c}\left(P_{f c}\right)
$$

with: $P_{f c}$ - the power produced by the FC $[\mathrm{kW}], N_{\text {cell }}$ - the number of cells, $M_{H_{2}}$ - the hydrogen molar mass $\left[\mathrm{gram} \cdot \mathrm{mol}^{-1}\right], F$ - the Faraday constant $\left[\mathrm{C} \cdot \mathrm{mol}^{-1}\right]$, $I_{f c}$ - the FC current $[\mathrm{A}]$, the instantaneous hydrogen flow values have been obtained for $P_{f c} \in[0,35] \mathrm{kW}$. Subsequently, a static model of the fuel cell is determined by interpolation methods, in order to formulate and evaluate the proposed energy management strategies. Thus, the interpolation of the instantaneous $\phi_{H_{2}}$ values is approximated by the second order polynomial:

$$
\phi_{H_{2}}=a_{2} P_{f c}^{2}+a_{1} P_{f c}+a_{0}
$$

where: $a_{2}=0.0235, a_{1}=0.1535, a_{0}=0.0095$.

The interpolation yields the approximation of the static $\phi_{H_{2}}-P_{f c}$ characteristics illustrated in Fig. 2. The polynomial approximation from equation (2) is used in Section III to

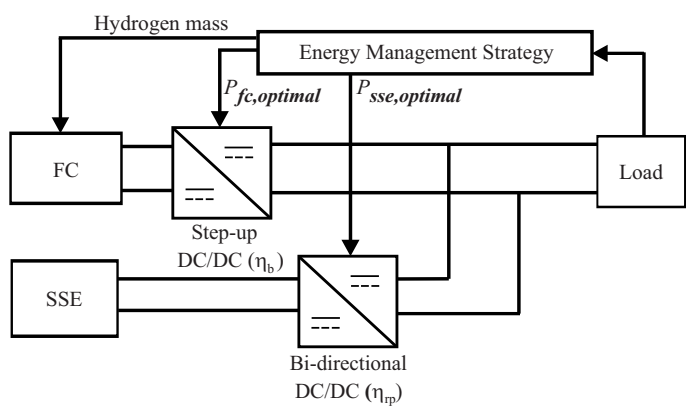

Fig. 1. Fuel cell/secondary storage element architecture

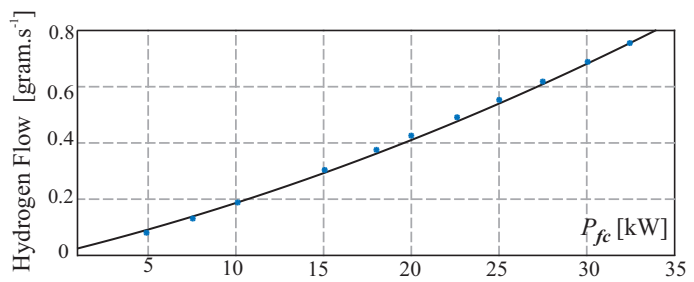

Fig. 2. Hydrogen flow $\phi_{\mathrm{H}_{2}}$ : simulated values obtained using Pukrushpan's model $(*)$, polynomial approximation (solid line).

formulate the cost function for different optimization methods. As it concerns the FC dynamics, it is taken into consideration as constrains of the optimization problem.

\section{B. Secondary storage element model}

The scaled SSE state of energy is defined as: $\operatorname{SoE}(t)=$ $\frac{E_{s s e}(t)}{E_{s s e, \max }}$, where $E_{s s e}(t)$ represents the instantaneous energy stored in the SSE and $E_{s s e, \max }$ is the maximum energy capacity of SSE. The scaling is necessary to avoid numerical problems that might appear in the resolution of the optimization problems.

The dynamics of SSE is expressed in function of the power demand and the FC power, using the power balance equation, as follows:

$$
\frac{d S o E}{d t}(t)=-\frac{P_{s s e}(t)}{E_{s s e, \max }}=-\frac{P_{\text {load }}(t)-\eta_{b} P_{f c}(t)}{\eta_{r p} E_{s s e, \max }}
$$

with: $\eta_{b}, \eta_{r p}$ - the efficiencies of DC-DC step-up and bidirectional power converters used to interconnect the $\mathrm{FC}$ and the SSE to the DC link, $P_{\text {load }}$ - the power demand, $P_{\text {sse }}$ - the power supplied by the SSE.

Given the fact that the EMS in Section III are formulated in discrete time, the discretized dynamics of SSE is approximated by:

$$
\operatorname{SoE}(k+1)=\operatorname{SoE}(k)-\frac{P_{\text {load }}(k)-\eta_{b} P_{f c}(k)}{\eta_{r p} E_{\text {sse }, \max }} \triangle t
$$

where $\triangle t$ is the sampling time.

Hence, concerning the energy management problem, the SSE choice (battery or supercapacitor) is not necessary at this stage of the study. 


\section{Vehicle model}

The profile of the power demand is determined using the vehicle dynamics [21], which takes into consideration the speed variation, the losses due to rolling and to aerodynamic drag, and the gravity:

$P_{\text {load }}=V\left[0.5 \rho_{\text {air }} V^{2} S C_{x} x+M\left(g \sin (\alpha)+\frac{d V}{d t}+g C_{r} \cos (\alpha)\right)\right]$

with: $M$ - the vehicle mass, $V$ - the vehicle velocity, $S$ - the frontal surface, $C_{x}$ - the drag coefficient, $\alpha$ - the road slope, $\rho_{\text {air }}$ - the air density, $g$ - the gravity acceleration, $C_{r}$ - the rolling resisting coefficient.

Generally, the velocity information comes from standard driving cycles or real-world driving cycles [6]. In this study, simulations of the proposed energy management strategies are performed using Artemis urban driving cycle [22], presented in section IV. This driving cycle provides an accurate representation of real driving conditions in urban environment.

\section{ENERGY MANAGEMENT STRATEGIES}

The main objective of the energy management system is to optimize the power split between the fuel cell and the SSE while ensuring that the SSE state of energy at the end of the driving cycle, noted $\operatorname{SoE}\left(T_{\text {cycle }}\right)$, reaches the initial energy level $\operatorname{SoE}\left(t_{0}\right)$. At the beginning of the driving cycle, the SSE is considered to be charged at a reference value $S o E_{r e f}$ and the optimization is performed by guaranteeing that the same energy level is achieved at the end of the cycle. The optimization implies minimizing the fuel consumption, represented by the hydrogen mass consumption of the fuel cell. Finally, the optimization solution yields the optimal power references $P_{f c, \text { optimal }}$ and $P_{\text {sse,optimal }}$ of the FC and SSE respectively.

\section{A. Optimization problem formulation}

In order to find the optimal FC power $P_{f c}$, the following discrete-time cost function is considered:

$$
J=\sum_{k=t_{0}}^{T_{\text {cycle }}} \phi_{H_{2}}(k)
$$

with $\phi_{H_{2}}$ defined in (1).

The minimization of the cost function $J$ is done subject to constraints issued from the physical limits of the system. First, the FC power and the SSE power are bounded by $\min / \max$ values noted: $P_{f c, \min }(\geq 0), P_{f c, \max }, P_{s s e, \min }$, $P_{\text {sse,max }}$. Moreover, the FC power variation between consecutive sampling instants $\triangle P_{f c}$ is restrained in the range $\left[\triangle P_{f c, \text { min }}, \triangle P_{f c, \text { max }}\right]$. Secondly, the state of energy $S o E$ is limited in the interval $\left[S o E_{\min }, S o E_{\max }\right]$. Consequently, the optimization problem to be solved is the following:

$$
\min _{P_{f c}(k)} J
$$

subject to:

$$
\text { dynamics (4) }
$$

$$
P_{f c, \min } \leq P_{f c}(k) \leq P_{f c, \max }
$$

$$
\begin{gathered}
P_{\text {sse }, \text { min }} \leq P_{\text {sse }}(k) \leq P_{\text {sse } \text { max }} \\
\left(\triangle P_{f c, \text { min }}+P_{f c}(k)\right) \leq P_{f c}(k+1) \leq\left(\triangle P_{f c, \max }+P_{f c}(k)\right) \\
S o E_{\text {min }} \leq \operatorname{SoE}(k) \leq S o E_{\max }
\end{gathered}
$$

In the next subsections, three optimization strategies (DP, MPC and ECMS) are proposed to compute the optimal fuel cell power that minimizes the hydrogen consumption subject to $S o E$ dynamics and the imposed constraints.

\section{B. Dynamic programming}

Dynamic programming involves the recursive resolution of the optimization problem (7)-(8) backwards in time, by applying Bellman's optimality principle [11]. Hence, considering the $S o E$ dynamics defined in (4), the final value of the SSE energy $\operatorname{SoE}\left(T_{\text {cycle }}\right)$ will be equal to its initial value $\operatorname{SoE}\left(t_{0}\right)\left(=S o E_{\text {ref }}\right)$. Here, a graph's resolution [11] is adopted, which is elaborated in 3 steps.

\section{- Step 1}

An admissible space $\Omega(k)$ of $\operatorname{SoE}(k)$ variations at each sampling instant is defined, that allows to minimize the computation time, without considering all possible values of $S o E(k)$ in the interval $\left[S o E_{\min }, S o E_{\max }\right]$ :

$$
\Omega(k)=\Omega_{\min }(S o E)(k): \triangle x: \Omega_{\max }(S o E)(k)
$$

where

$$
\begin{gathered}
\left.\Omega_{\max }(S o E)(k)=\max \left(S o E_{b, \max }, S o E_{f, \max }, S o E_{\max }\right)\right) \\
\left.\Omega_{\min }(S o E)(k)=\min \left(S o E_{b, \min }, S o E_{f, \min }, S o E_{\min }\right)\right)
\end{gathered}
$$

and $\triangle x$ is the state space sampling step.

The forward and backward evolutions of $S o E$ dynamics are calculated using the following relations:

$\left\{\begin{array}{l}S o E_{f, \max }(k+1)=S o E_{f, \max }(k)-\min \left(\frac{P_{\text {load }}(k)-\eta_{b} P_{f c}(k)}{\eta_{r p} E_{s s e, \max }}\right) \\ \operatorname{SoE}_{f, \min }(k+1)=S o E_{f, \min }(k)-\max \left(\frac{P_{l o a d}(k)-\eta_{b} P_{f c}(k)}{\eta_{r p} E_{s s e, \max }}\right)\end{array}\right.$

$k=0: T_{\text {cycle }}-1$

$\left\{\begin{array}{l}S_{o E_{b, \max }}(k)=S o E_{b, \max }(k+1)+\max \left(\frac{P_{l o a d}(k)-\eta_{b} P_{f c}(k)}{\eta_{r p} E_{s s e, \max }}\right) \\ S_{o E_{b, \min }}(k)=S o E_{b, \min }(k+1)+\min \left(\frac{P_{l o a d}(k)-\eta_{b} P_{f c}(k)}{\eta_{r p} E_{s s e, \max }}\right)\end{array}\right.$

$k=T_{\text {cycle }}-1:-1: 0$

\section{- Step 2}

The resolution algorithm, given by Algorithm 1, analyzes all the admissible trajectories of $\operatorname{SoE}(k)$ inside $\Omega(k)$ and computes the optimal values of FC power. Once these values are determined for the whole driving cycle, they are stored in a look-up table. Also, an indices look-up table is obtained that allows to find the minimum cost trajectory inside the look-up table containing the optimal values of $P_{f c}$.

\section{Algorithm 1. Dynamic Programming: off-line resolution}

1. $N_{t}=\frac{T_{\text {cycle }}-t_{0}}{\triangle t}$;

2. for $k=N_{t}:-1: 1$

3. $\Omega_{k}=\Omega_{\min }(S o E)(k): \triangle x: \Omega_{\max }(S o E)(k)$; 
4. $\Omega_{k-1}=\Omega_{\min }(S o E)(k-1): \triangle x: \Omega_{\max }(S o E)(k-1)$;

5. $\quad c_{k} \leftarrow$ length $\left(\Omega_{k}\right)$

6. $\quad c_{k-1} \leftarrow$ length $\left(\Omega_{k-1}\right)$;

7. for $i=1: c_{k-1}$

8. for $j=1: c_{k}$

9. $\quad \operatorname{cost}(j)=\phi_{H_{2}}(i \rightarrow j)+\operatorname{cost}_{k}(j)$

$\operatorname{cost}_{k}(j)$ is the total cost that leads the state $S o E^{j} \in \Omega_{k}$

to the final value $\operatorname{SoE}\left(T_{\text {cycle }}\right)$

$\phi_{H_{2}}(i \rightarrow j)$ is the cost that leads the state

$S o E^{i} \in \Omega_{k-1}$ to $S o E^{j} \in \Omega_{k}$

10. end for

11. Find minimum of $\operatorname{cost}\left(1: c_{k}\right)$ and save it on $\operatorname{cost}_{k-1}(i)$

12. end for

13. end for

\section{- Step 3}

Using the indices look-up table and Algorithm 2, the optimal power sequence is found and applied to system (4).

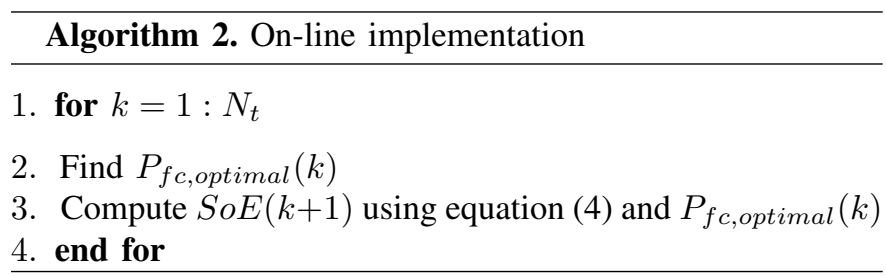

\section{Equivalent consumption minimization strategy}

The principle of equivalent consumption minimization strategy (ECMS) derives from the conversion of the energy stored in the SSE into fuel consumption. The equivalence is made by introducing a positive conversion factor $\lambda\left[\operatorname{gram} \cdot \mathrm{J}^{-1}\right]$. Thus, the equivalent fuel consumption $\gamma_{e q}$ is defined as:

$$
\gamma_{e q}(k)=\phi_{H_{2}}(k)+\lambda P_{s s e}(k)
$$

Using the power balance equation:

$$
P_{f c}(k)=\frac{P_{\text {load }}(k)-\eta_{r p} P_{s s e}(k)}{\eta_{b}}
$$

and the relation (2), the optimization problem minimizing $\gamma_{e q}$ is formulated as follows:

$$
\min _{P_{s s e}(k)} \beta_{2} P_{s s e}^{2}(k)+\beta_{1} P_{s s e}(k)+\beta_{0}+\lambda(k) P_{s s e}(k)
$$

with: $\beta_{2}=a_{2} \frac{\eta_{r p}^{2}}{\eta_{b}^{2}}, \beta_{1}=-\frac{\eta_{r p}}{\eta_{b}}\left(2 \frac{a_{2}}{\eta_{b}} P_{l o a d}+a_{1}\right)$ and $\beta_{0}=$ $\frac{a_{2}}{\eta_{b}^{2}} P_{\text {load }}^{2}+\frac{a_{1}}{\eta_{b}} P_{\text {load }}+a_{0}$.

The ECMS computes the instantaneous optimal value $P_{\text {sse,optimal }}(k)$ using the current value of the power demand, while $P_{f c, \text { optimal }}(k)$ is determined using equation (13). The choice of parameter $\lambda$ influences the SSE charge and discharge processes over the driving cycle. In the literature, several approaches have been considered [23] to balance the SSE energy level during the cycle, such that the $\operatorname{SoE}(k)$ lies between the boundary values and the same SSE energy capacity is obtained at the beginning and at the end of the cycle. Here, the conversion factor is chosen as a proportional controller
$\lambda(k)=s_{0}+s_{1}\left(S o E_{r e f}-S o E(k)\right)$ [23], where $s_{0}$ and $s_{1}$ represent equivalence factors. Their values are tuned in function of the driving cycle and usually are adapted to driving conditions (acceleration phase, breaking phase, road slope).

\section{Model Predictive Control}

Model predictive control (MPC) strategy consists in computing an optimal sequence of the input variable that minimizes a cost function over a finite prediction horizon $N_{p}$ with respect to a prediction model and constraints imposed on the model input and states. The optimal sequence is determined at each sampling instant and according to the receding horizon policy, only the first element of the sequence is applied to the system. Then, the procedure is repeated using the updated state.

Let us define the extended state vector: $x_{e}(k)=$ $\left[S o E(k), P_{f c}(k-1)\right]^{\prime}$ and the fuel cell power variation between two successive sampling instants: $\triangle P_{f c}(k)=P_{f_{c}}(k)-$ $P_{f c}(k-1)$.

The state-space representation of the prediction model has the following expression:

$$
\left\{\begin{array}{l}
x_{e}(k+1)=A x_{e}(k)+B \triangle P_{f c}(k)+D P_{l o a d}(k) \\
y(k)=C x_{e}(k)
\end{array}\right.
$$

with: $A=\left(\begin{array}{cc}1 & \frac{\eta_{b} \Delta t}{\eta_{r p} E_{s e e, m a x}} \\ 0 & 1\end{array}\right) ; B=\left(\begin{array}{c}\frac{\eta_{b} \Delta t}{\eta_{r p} E_{s e e, m a x}} \\ 1\end{array}\right)$

$$
D=\left(\begin{array}{c}
\frac{-\triangle t}{\eta_{r p} E_{s e e, \max }} \\
0
\end{array}\right) ; C=\left(\begin{array}{ll}
1 & 0
\end{array}\right)
$$

The optimization problem is formulated as a tracking problem, where the cost function to be minimized consists of the error between the $S o E(k)$ and its reference value $S o E_{r e f}$, and of the variation $\triangle P_{f c}(k)$ :

$\min _{\triangle P_{f c}(k)} \sum_{i=1}^{N_{p}}\left\|Q\left(y(k+i)-y_{r e f}(k+i)\right)\right\|_{2}+\left\|R \triangle P_{f c}(k+i-1)\right\|_{2}$

subject to: $\quad$ state-space model (15)

$$
\begin{gathered}
x_{e, \min } \leq x_{e}(k) \leq x_{e, \max } \\
\triangle P_{f c, \min } \leq \triangle P_{f c}(k) \leq \triangle P_{f c, \max }
\end{gathered}
$$

where $Q$ and $R$ are weight matrices.

Considering the following sequence to be optimized $\triangle \overline{P_{f c}}(k)=\left[\triangle P_{f c}(k), \cdots, \triangle P_{f c}\left(k+N_{p}-1\right)\right]^{\prime}$ and the power demand sequence $\overline{P_{\text {load }}}(k)=\left[P_{\text {load }}(k), \cdots, P_{\text {load }}\left(k+N_{p}-\right.\right.$ $1)]^{\prime}$, the quadratic optimization problem (16) can be rewritten in the following form:

$$
\begin{aligned}
& \min _{\triangle \overline{P_{f c}}(k)} 0.5 \triangle \overline{P_{f c}}(k)^{\prime} H \triangle \overline{P_{f c}}(k)+\left(x_{e}(k)^{\prime} F_{1}+\overline{P_{\text {load }}}(k)^{\prime} F_{2}\right. \\
& \left.+\left[S o E_{\text {ref }}, *\right] F_{3}\right) \triangle \overline{P_{f c}}(k)
\end{aligned}
$$

subject to:

$$
\Gamma \triangle \overline{P_{f c}}(k) \leq X_{e, \max }-\Phi x_{e}(k)-\Psi \overline{P_{\text {load }}}(k)
$$




$$
\begin{gathered}
\Gamma \triangle \overline{P_{f c}}(k) \leq-X_{e, \min }+\Phi x_{e}(k)+\Psi \overline{P_{\text {load }}}(k) \\
\triangle P_{f c, \text { min }} \leq \triangle P_{f c}(k+i) \leq \triangle P_{f c, \max }, i=0: N_{p}-1
\end{gathered}
$$

where $X_{e, \max }=\left[x_{e, \max }, \cdots, x_{e, \max }\right]^{\prime}, X_{e, \min }=$ $\left[x_{e, \min }, \cdots, x_{e, \min }\right]^{\prime}, \quad x_{e, \max }=\left[S o E_{\max }, P_{f c, \max }\right]$ and $x_{e, \min }=\left[S o E_{\text {min }}, P_{f c, m i n}\right]$.

The matrices $H, F_{1}, F_{2}, F_{3}, \Phi, \Gamma$ and $\Psi$ are defined as follows:

$$
\begin{aligned}
& H=\Gamma^{\prime} \bar{Q} \Gamma+\bar{R} ; \quad F_{1}=\Phi^{\prime} \bar{Q} \Gamma ; \quad F_{2}=\Psi^{\prime} \bar{Q} \Gamma ; \\
& F_{3}=-\left(\begin{array}{llll}
I_{2} & I_{2} & \cdots & I_{2}
\end{array}\right) \bar{Q} \Gamma ; \Phi=\left(\begin{array}{llll}
A & A^{2} & \cdots & A_{e}^{N_{p}}
\end{array}\right)^{\prime} ; \\
& \Gamma=\left(\begin{array}{cccc}
B & 0 & \cdot & 0 \\
A B & B & \cdot & 0 \\
\cdot & \cdot & \cdot & \cdot \\
\cdot & \cdot & \cdot & \cdot \\
A^{N_{p}-1} B & \cdot & \cdot & B
\end{array}\right) ; \Psi=\left(\begin{array}{cccc}
D & 0 & \cdot & 0 \\
A D & D & \cdot & 0 \\
\cdot & \cdot & \cdot & \cdot \\
\cdot & \cdot & \cdot & \cdot \\
A^{N_{p}-1} D & \cdot & \cdot & D
\end{array}\right)
\end{aligned}
$$

with: $\bar{Q}=\operatorname{diag}\left(C^{T} Q C, \cdots, C^{T} Q C\right) ; \bar{R}=\operatorname{diag}(R, \cdots, R)$.

Therefore, the resolution of the optimization problem (17)-(18) requires the knowledge or the estimation of the power demand over the prediction horizon. At each sampling instant, the supervisor system computes the optimal sequence $\triangle{\overline{P_{f c}}}^{*}(k)$ and uses its first element $\triangle P_{f c}^{*}(k)$ to determine the optimal power $P_{f c \text {,optimal }}$ that the fuel cell should provide. Then, using equation (13), the optimal SSE power $P_{\text {sse,optimal }}$ is calculated.

\section{Simulation RESUlts}

The analyzed optimization-based strategies are applied to a FC/SSE system of an electric vehicle and their performances are evaluated in simulation using the Artemis driving cycle. The considered secondary storage element is a supercapacitor with a maximal energy capacity of $E_{\text {sse, } \max }=150[\mathrm{~kJ}]$. The vehicle parameters are given in Table I. Fig. 3 shows the velocity and power demand corresponding to Artemis cycle. The power demand has been derived using equation (5) and a road slope $\alpha$ of $5 \%$ between $t \in[400,600]$ s and 0 otherwise. The limits and the parameters of the multi-source system are presented in Table II.

The DP algorithm was performed for an admissible space of $S o E$ defined with a state space sampling $\triangle x=0.001$ and a sampling time $\triangle t=1 \mathrm{~s}$. The optimal FC power over the whole cycle is illustrated in Fig. 4(a). The algorithm guarantees that the state of energy of SSE stays in the admissible space in the presence of constraints (positive $P_{f c}$, limited $\triangle P_{f c}$ ) and that the initial value of SSE energy is obtained at the end of the cycle $\left(\operatorname{SoE}\left(T_{\text {cycle }}\right)=\operatorname{SoE}\left(t_{0}\right)\right)$, as shown in Fig. 4(b). The ECMS optimization problem (14) was solved using the equivalence factors $s_{0}, s_{1} \in[1.5,2] \cdot 10^{-5}$. Fig. 5 shows the fuel cell power and the state of energy obtained with ECMS approach. At the end of the driving cycle, the energy stored in the SSE approximates the initial value with an error of $3.8 \%$.

The MPC strategy has been implemented using the prediction horizon $N_{p}=20$, the weight matrices $Q=10^{5}, R=10^{5}$ and the lower/upper bounds of $P_{f c}, \triangle P_{f c}$ and $S o E$ given in Table II. To demonstrate the potential of this optimization
TABLE I

VEHICLE PARAMETERS

\begin{tabular}{|c|c|c|c|c|c|}
\hline$M[\mathrm{~kg}]$ & $S\left[\mathrm{~m}^{2}\right]$ & $C_{x}$ & $\rho_{\text {air }}\left[\mathrm{kg} \cdot \mathrm{m}^{-3}\right]$ & $g\left[\mathrm{~m} \cdot \mathrm{s}^{-2}\right]$ & $C_{r}$ \\
\hline 1500 & 2.5 & 0.3 & 1.225 & 9.8 & 0.01 \\
\hline
\end{tabular}

TABLE II

Multi-SOURCE System Limits ANd PARAMETERS

\begin{tabular}{|l|l|l|}
\hline$P_{f c, \max }=35[\mathrm{~kW}]$ & $\triangle P_{f c, \max }=4[\mathrm{~kW}]$ & $\eta_{b}=0.95$ \\
\hline$P_{f c, \min }=0[\mathrm{~kW}]$ & $\triangle P_{f c, \min }=-4[\mathrm{~kW}]$ & $\eta_{r p}=1$ \\
\hline$P_{s s e, \max }=10[\mathrm{~kW}]$ & $S o E_{\min }=0.25$ & \\
\hline$P_{s s e, \min }=-10[\mathrm{~kW}]$ & $S o E_{\max }=1$ & \\
\hline
\end{tabular}

strategy, the power load profile has been considered to be known over the prediction horizon, assumption that can be removed by estimating the power demand. Fig. 6 shows that the constraints on the FC power and $S o E$ are satisfied. In this case, a $3 \%$ error between the final and the initial values of $S o E$ is obtained.

The performances of the proposed energy management strategies are compared in terms of hydrogen mass consumption. Table III illustrates the fuel consumption and the fuel economy determined using the analyzed optimization methods. Also, the fuel consumption in the absence of the additional storage element is provided.

The on-line approaches (ECMS and MPC) yield close suboptimal results concerning the fuel consumption, compared to the DP optimal result. Although, the fuel economy percentage obtained using MPC is promising in comparison to the value determined using ECMS. However, the MPC provides an optimistic result due to the assumption of a known power demand over the optimization window. On the other hand, the drawback of ECMS is the lack of an accurate method to determine $s_{0}, s_{1}$ parameters. Still, the main advantage of the on-line methods is the low computation complexity that eases their real-time implementation.

TABLE III ENERGY MANAGEMENT STRATEGIES COMPARISON

\begin{tabular}{|c|c|c|}
\hline Strategy & Fuel consumption [gram] & Fuel economy (\%) \\
\hline SSE omitted & 78.93 & - \\
\hline DP & 53.21 & $32.58 \%$ \\
\hline ECMS & 55.31 & $29.92 \%$ \\
\hline MPC & 54.31 & $31.19 \%$ \\
\hline
\end{tabular}

\section{Conclusions}

Energy management strategies have been analyzed for an electric vehicle with the aim of optimizing the global efficiency of the powertrain system, by minimizing the fuel consumption. On-line strategies, such as ECMS and MPC, have been evaluated using an urban driving cycle and have been compared to an optimal strategy (DP), that presents a high computational time and needs a large storage capacity for real-time application. The optimization strategies comparison has shown that the on-line approaches admit satisfying results 

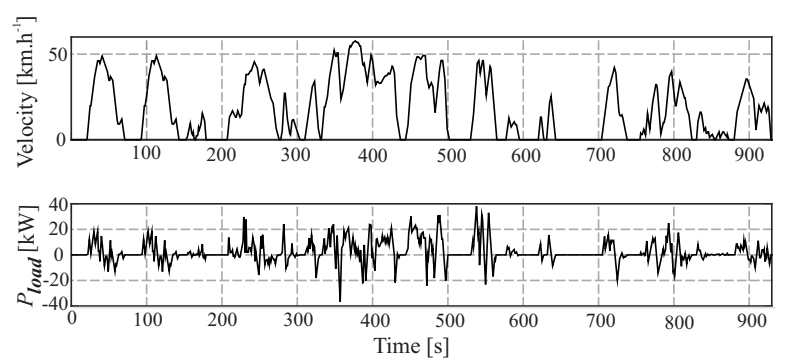

Fig. 3. Artemis driving cycle
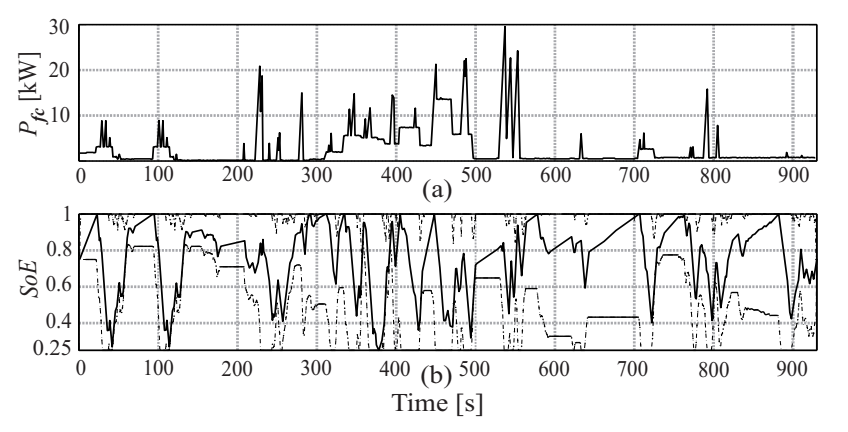

Fig. 4. DP: (a) Fuel cell power, (b) Supercapacitor sate of energy ( $S o E)$ (solid line), admissible space $\Omega$ (dash-dot line).

in terms of fuel economy, computation complexity and ease of elaboration.

As perspectives of this work, the analyzed energy management strategies could be tested on a global model of the multi-source system that includes the fuel cell dynamics and the internal control loops of DC-DC power electronic devices used to interconnect the multiple energy/storage sources.

\section{REFERENCES}

[1] J. Zhuo, C. Chakrabarti, K. Lee, N. Chang, and S. Vrudhula. Maximizing the lifetime of embedded systems powered by fuel cell-battery hybrids. IEEE Transactions on Very Large Scale Integration (VLSI) systems, 17:22-32, 2009.

[2] M. Cacciato, F. Caricchi, F. Capponi, and E. Santini. A critical evaluation and design of bi-directional $\mathrm{dc} / \mathrm{dc}$ converters for supercapacitors interfacing in fuel cell applications. In Industry Applications Conference, 2004.

[3] L. N. Degliuomini, D. Zumoffen, M. Basualdo, D. Feroldi, and J. Rierac. Adaptive predictive robust control for fuel cells hybrid vehicles. In Vehicle Power and Propulsion Conference, 2010.

[4] D. Gao, Z. Jin, and Q. Lu. Energy management strategy based on fuzzy logic for a fuelcell hybrid bus. Journal of Power Sources, 185:311-317, 2008.

[5] Q. Li, W. Chen, Z. Liu, M. Li, and L. Ma. Development of energy management system based on a power sharing strategy for a fuel cell-battery-supercapacitor hybrid tramway. Journal of Power Sources, 279:267-280, 2015.

[6] G. Rousseau, D. Sinoquet, A. Sciarretta, and Y.Milhau. Design optimization and optimal control for hybrid vehicles. In International Conference on Engineering Optimization, EngOpt, 2008.

[7] N. Kim, S. Cha, and H. Peng. Optimal control of hybrid electric vehicles based on pontryagin's minimum principle. Control Systems Technology, 19:1279 - 1287, 2010.

[8] L. Johannesson and B. Egardt. Approximate dynamic programming applied to parallel hybrid powertrains. In Proceedings of the 17th World Congress IFAC, 2008.

[9] A. Ravey. Design and control strategy of powertrain in hybrid electric vehicles. PhD thesis, University of Technology of Belfort-Montbéliard, 2013.
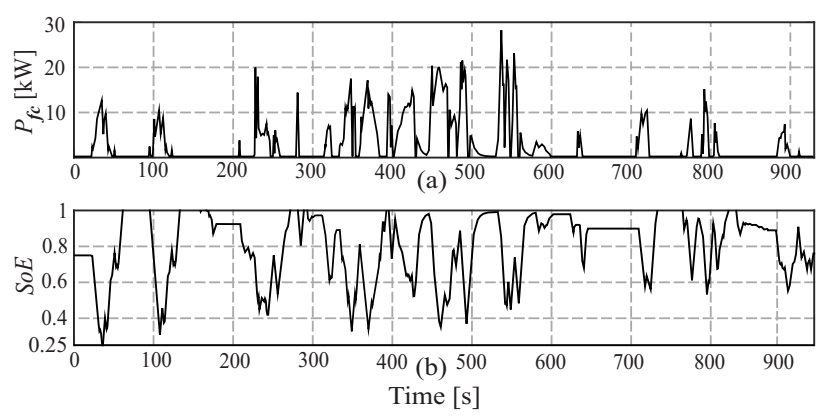

Fig. 5. ECMS: (a) Fuel cell power, (b) Supercapacitor sate of energy (SoE).
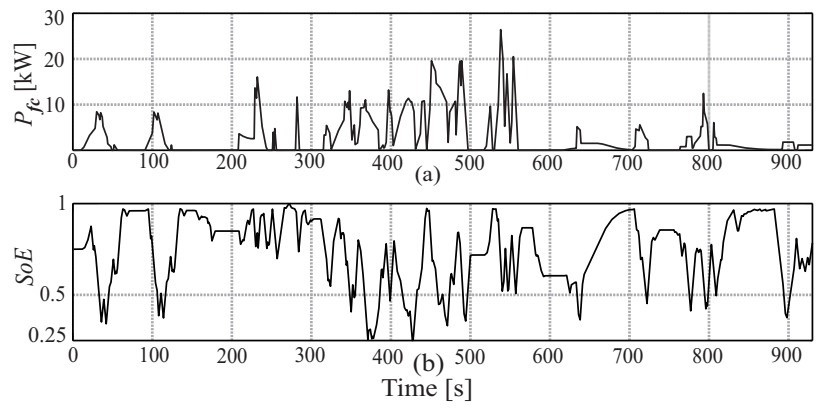

Fig. 6. MPC: (a) Fuel cell power, (b) Supercapacitor sate of energy (SoE).

[10] L. V. Perez, G. R. Bossio, D. Moitre, and G. O. Garcia. Optimization of power management in an hybrid electric vehicle using dynamic programming. Mathematics and Computers in Simulation, 73:244-254, 2006.

[11] S. Delprat. Évaluation de stratégies de commande pour véhicules hybrides parallèles. PhD thesis, Université de Valenciennes, 2002.

[12] G. Paganelli, S. Delprat, T. M. Guerra, J. Rimaux, and J. J. Santin. Equivalent consumption minimization strategy for parallel hybridpowertrains. In Vehicular Technology Conference, 2002.

[13] A. Sciarretta, M. Back, and L. Guzzella. Optimal control of parallel hybrid electric vehicles. Control Systems Technology, 12:352-363, 2004.

[14] J. P. Torreglosa, F. Jurado, P. García, and L. M. Fernández. Hybrid fuel cell and battery tramway control based on an equivalent consumption minimization strategy. Control Engineering Practice, 19:1182-1194, 2011.

[15] K. Koprubasi P. Pisu and G. Rizzoni. Energy management and drivability control problems for hybrid electric vehicles. In 44th IEEE Conference on Decision and Control, and the European Control Conference, 2005.

[16] A. Chasse and A. Sciarretta. Supervisory control of hybrid powertrains: An experimental benchmark of offline optimization and online energy management. Control Engineering Practice, 19:1253-1265, 2011.

[17] P. García, J. P. Torreglosa, L. M. Fernández, and F. Jurado. Control strategies for high-power electric vehicles powered by hydrogen fuel cell, battery and supercapacitor. Expert Systems with Applications, 40:4791-4804, 2013.

[18] Q. Chen, L. Gaob, R. A. Dougal, and S. Quana. Multiple model predictive control for a hybrid proton exchange membrane fuel cell system. Journal of Power Sources, 191:473-482, 2009.

[19] S. Caux, W. Hankache, M. Fadel, and D. Hissel. Pem fuel cell model suitable for energy optimization purposes. Energy Conversion and Management, 51:320-328, 2010.

[20] J. T. Pukrushpan. Modeling and control of fuel cell systems and fuel processors. PhD thesis, University of Michigan, 2003.

[21] R. Mosdale. Transport électrique routier - véhicules électriques à pile à combustible. Technical report, Techniques de l'ingénieur, 2003.

[22] M. André. The Artemis European driving cycles for measuring car pollutant emissions. Science of the Total Environment, 334-335:73-84, 2004.

[23] T. Hofman and M. Steinbuch. Rule-based energy management strategies for hybrid vehicles. Electric and Hybrid Vehicles, 1:71-94, 2007. 